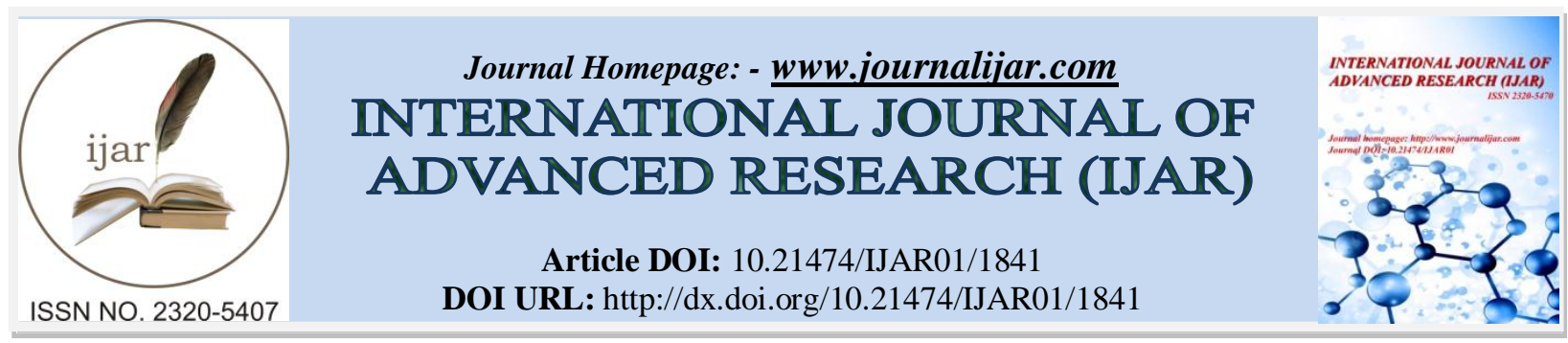

RESEARCH ARTICLE

\title{
EFFECT OF MAGNESIUM DOPING ON THE STRUCTURAL STABILITY OF LAYERED LINIO BASED CATHODE MATERIALS.
}

\author{
N. Murali ${ }^{*}, 1,2$, K. Ephraim Babu ${ }^{3}$, S. J. Margarette ${ }^{2}$, J. M. Sailaja ${ }^{2}$ and V. Veeraiah ${ }^{2}$. \\ 1. Advanced Analytical Laboratory, DST-PURSE Programme, Andhra University \\ 2. Department of Physics, Andhra University, Visakhapatnam, Andhra Pradesh, India \\ 3. Department of Physics, Narasaraopeta Engineering College (A). Narasaraopet, A.P.
}

\section{Manuscript Info}

Manuscript History

Received: 16 August 2016

Final Accepted: 22 September 2016

Published: October 2016

Key words:-

Layered structure, XRD, FESEM, FTIR.

\section{Abstract}

In rechargeable lithium batteries, nickel is employed in the form of oxide in which lithium ions are inserted into its crystal structure to form layered nickel oxide i.e., $\mathrm{LiNiO}_{2}$. The objective of this paper is to understand the effects of substitution of magnesium on the structural stability in the layered intercalation compounds. The compounds $\mathrm{LiNiO}_{2}$ and $\mathrm{LiNi}_{0.75} \mathrm{Mg}_{0.25} \mathrm{O}_{2}$ are synthesized by a solid state reaction method under the flow of air at $\quad 800{ }^{\circ} \mathrm{C}$ for 24 hours. The influence of doping $\mathrm{Mg}$ on structure, morphology and bonding nature of cathode materials are investigated systematically. From the $\mathrm{x}$-ray diffraction (XRD) data, the intensity versus diffraction angle peak indicated that the compound crystallized as a rhombohedral system (space group $R \overline{3} m$ ). The lattice constants and crystallite sizes were computed from XRD data. The particle morphology of the compound was observed using a field effect scanning electron microscope (FESEM). The FT-IR spectroscopic data of $\mathrm{LiNiO}_{2}$ revealed the local structure of the oxide lattice constituted by $\mathrm{LiO}_{6}$ and $\mathrm{NiO}_{6}$ octahedra.

Copy Right, IJAR, 2016,. All rights reserved.

\section{Introduction:-}

Over the last two decades, intensive research is going on to improve the overall performance of lithium ion batteries. The main focus has been in search of the alternative cathode materials, apart from the regular components of battery mechanisms. For the cathode materials, every system has its own advantages and disadvantages. The $\mathrm{LiCoO}_{2}$ is a well known cathode material for rechargeable lithium ion batteries [1]. However, due to its high cost and toxicity, there has been a continuous demand during the last few years to develop alternative cathode materials which would be environmentally friendly and cost effective [2-3]. Metal based $\mathrm{LiNiO}_{2}, \mathrm{LiMn}_{2} \mathrm{O}_{4}$ and olivine type $\mathrm{LiFePO}_{4}$ are promising materials for future to substitute $\mathrm{LiCoO} 2$. The $\mathrm{LiNiO}_{2}$ is cheaper and less toxic compared to $\mathrm{LiCoO}_{2}$ [4]. It delivers a larger reversible capacity with a comparable life-cycle. It is considered to be one of the best cathode materials for Lithium ion cells. The electrochemical properties of cathodes based on $\mathrm{LiNiO}_{2}$ are good. The difficulty in synthesizing stoichiometric $\mathrm{LiNiO}_{2}$ is also due to the loss of lithium from the host structure during high temperature calcinations because of the high vapor pressure of lithium [5-6], thus leading to the formation of nonstoichiometric structure. However, its synthesis requires special care to obtain good and reproducible performances.

Corresponding Author:- N. Murali.

Address:- Advanced Analytical Laboratory, DST-PURSE Programme, Andhra University. 
The goal of this paper is the synthesis of $\mathrm{LiNiO}_{2}$ and $\mathrm{LiNi}_{0.75} \mathrm{Mg}_{0.25} \mathrm{O}_{2}$ using the solid state reaction method and understanding the correlation between the structures and bonding nature.

\section{Synthesis \& Experimental Techniques:}

The cathode compositions are synthesized by a solid state reaction from stoichiometric amounts of $\mathrm{Li}_{2} \mathrm{CO}_{3}$ (Himedia 99.9\%), $\mathrm{MgO}$ (Himedia 99.9\%) and $\mathrm{NiO}$ (Himedia 99.9\%).

$0.5 \mathrm{Li}_{2} \mathrm{CO}_{3}+\mathrm{NiO} \rightarrow \mathrm{LiNiO}_{2}+$ gas $\uparrow$

$0.5 \mathrm{Li}_{2} \mathrm{CO}_{3}+0.75 \mathrm{NiO}+0.25 \mathrm{MgO} \rightarrow \mathrm{LiNi}_{0.75} \mathrm{Mg}_{0.25} \mathrm{O}_{2}+$ gas $\uparrow$

A slight excess amount of lithium (4\%) is used to compensate for any loss of the metal which might have occurred during the calcining at high temperatures. The appropriate stoichiometric amount of the chemicals are ground in an agate mortar and calcined at $800^{\circ} \mathrm{C}$ for $24 \mathrm{~h}$ in air using a muffle box furnace.

The structural characteristics were determined by X-ray diffraction using a Rigaku $\mathrm{Cu}-\mathrm{K} \alpha$ diffractometer with diffraction angles of $10^{\circ}$ and $80^{\circ}$ in increments of $0.02^{\circ}$. The morphologies of the materials were studied by field emission scanning electron microscopy (FESEM) using Carl Zeiss, EVO MA 15, Oxford Instruments, Inca Penta FET x 3.JPG. The Fourier transform infrared spectra was recorded using Nicolet 6700 and following the $\mathrm{KBr}$ pressed pellet technique to determine the structures of the calcined powders.

\section{Structure of $\mathrm{LiNiO}_{2}:-$}

Most $\mathrm{ABO}_{2}$ oxides are related to the rock-salt structure and are either ordered or distorted forms of $\mathrm{NaCl}$ (Figure 1). One possibility, exemplified by $\mathrm{LiNiO}_{2}$ is a $1: 1$ ordering of the cation sites, which reduces the space group symmetry from $O_{h}^{5}$ (Fm3m structure) to a tetragonal $D_{4 h}^{19}$ (I41/amd structure with Z=3). The second possibility is a distortion of $\mathrm{NaCl}$ consisting of an elongation of the unit cell along the (111) direction; the space group is $R \overline{3} \mathrm{~m}$ with $\mathrm{Z}=1$. This arrangement is sometimes known as either the $\mathrm{NaHF}_{2}$-type structure or the $\alpha-\mathrm{NaFeO}_{2}$-type structure. A third structure $\gamma-\mathrm{LiAlO}_{2}$, which is not related to rock salt, consists of corner-linked tetrahedra in which both $\mathrm{Li}$ and $\mathrm{Al}$ are four-coordinated [7-8].
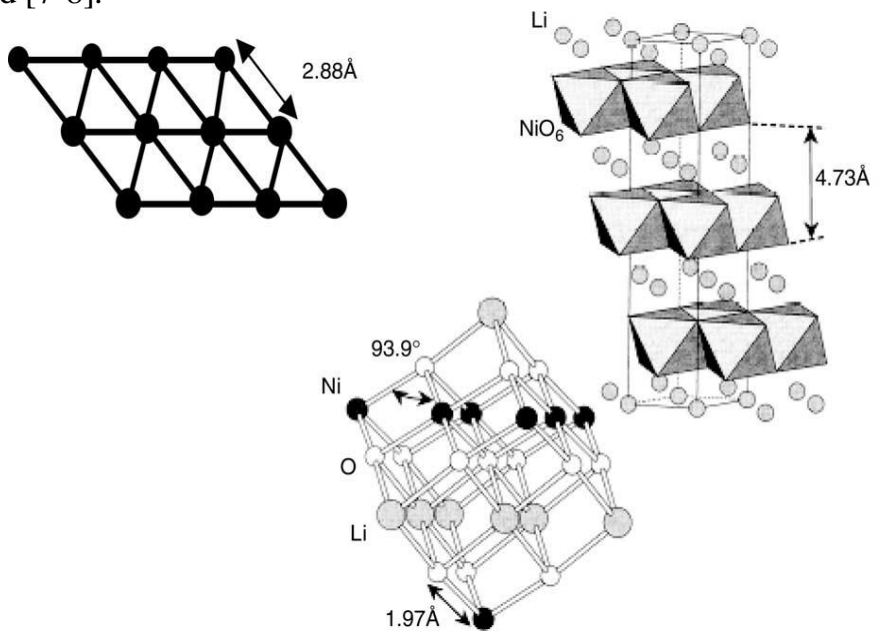

Figure 1:- Ideal structure of $\mathrm{NaFeO}_{2}$ [8]

The layered $\mathrm{LiMO}_{2}(\mathrm{M}=\mathrm{Co}, \mathrm{Mn}$ and $\mathrm{Ni})$ are traditional cathode materials that have been thoroughly studied experimentally and theoretically. The layered structure can be envisioned as two interpenetrating fcc lattices, one consisting of oxygen and the other consisting of alternating (111) planes of Li and Transition Metal (TM) ions. They all belong to the $R \overline{3} \mathrm{~m}$ space group and the structure can be described as the periodic distribution of layers of $\mathrm{MO}_{6}$ and $\mathrm{LiO}_{6}$ octahedra stacked in an alternate manner. In the $R \overline{3} m$ space group, the $\mathrm{Li}$ and the metal ions remain fixed in the ideal rock salt positions, but the whole (111) oxygen planes may relax in the (111) direction giving rise to different slab spaces that affect lithium mobility. Lithium manganese oxide $\left(\mathrm{LiMnO}_{2}\right)$ has the same layered structure as $\mathrm{LiCoO}_{2}$ and $\mathrm{LiNiO}_{2}$ as shown in figure 2 . 


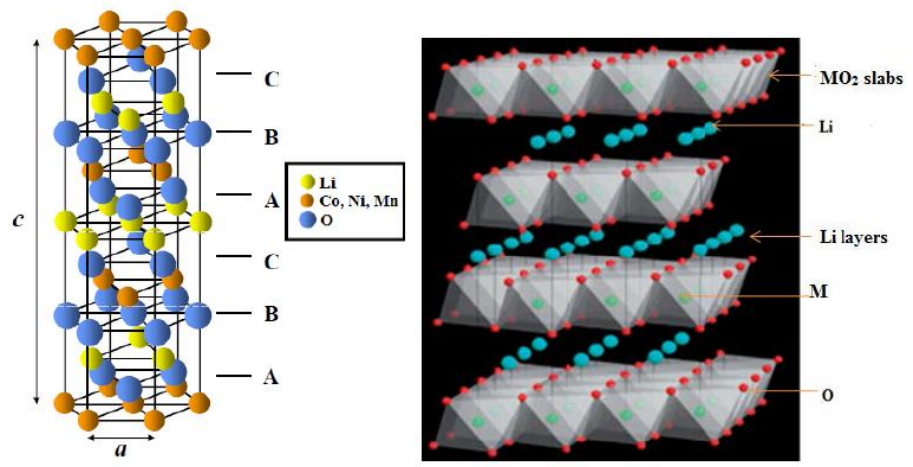

Figure 2:- The structure of layered $\mathrm{LiMO}_{2}(\mathrm{M}=\mathrm{Co}, \mathrm{Mn}$ and $\mathrm{Ni})$ materials.

\section{X-ray diffraction study:-}

The constructive interference of X-ray radiation occurs in a material when Bragg's law is satisfied:

$$
2 \mathrm{~d} \sin \theta=\mathrm{n} \lambda
$$

where $\mathrm{d}$ is the distance between equivalent atomic planes, $\theta$ is the angle between the incident beam and these planes, $\mathrm{n}$ is an integer and $\lambda$ is the wavelength. The scattered intensity can be measured as a function of scattering angle $2 \theta$. Analysis of the resulting X-ray diffraction (XRD) pattern is an efficient method for determining the different phases present in the sample. Since the wavelength of X-rays used is of the same order of magnitude as the interatomic distances and bond lengths in crystalline solids $(\sim 1 \AA)$, the XRD method serves well to determine the structure of crystalline materials.

In the ideal stoichiometric $\mathrm{LiNiO}_{2}$ (JCPDS \# 090063), the $\mathrm{Li}^{+}$and $\mathrm{Ni}^{3+}$ cations are supposed to be orderly arranged along the (111) direction of the rock salt cubic lattice leading to a $2 \mathrm{D}$ layer structure, isostructural with $\alpha-\mathrm{NaFeO}_{2}$. Hence, $\mathrm{LiNiO}_{2}$ has a rhombohedral structure with trigonal symmetry (space group: $R \overline{3} m$ ) comprising of two interpenetrating close packed FCC sub-lattices: one consists of oxygen anions, and the other consists of Li and $\mathrm{Ni}$ cations on alternating (111) planes [8].

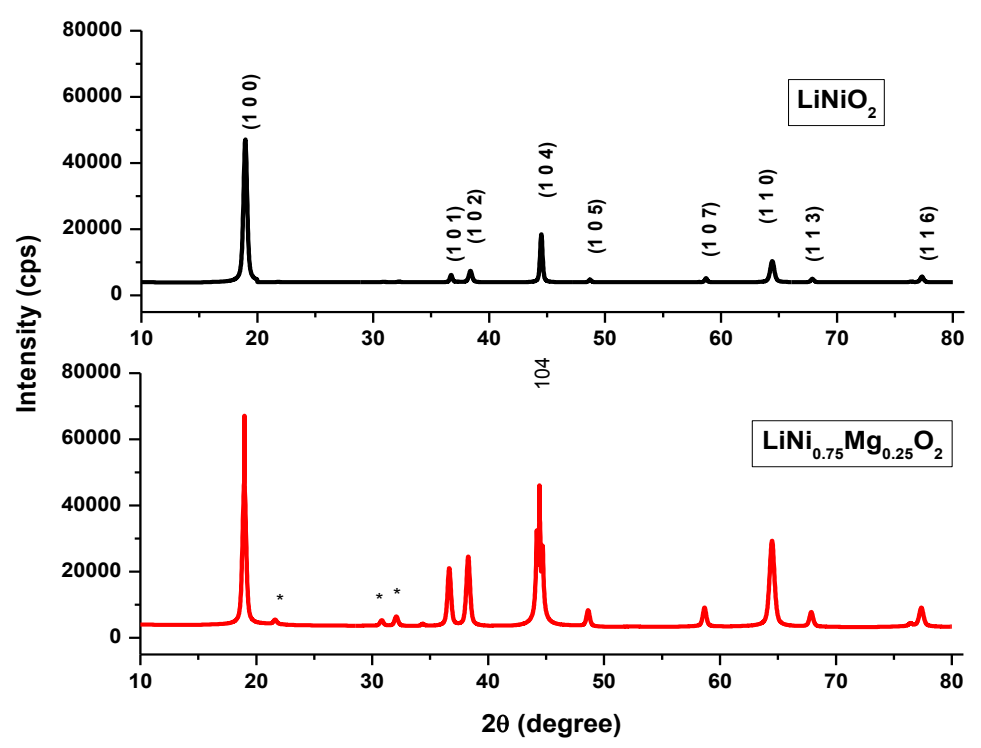

Figure 3:- $\mathrm{XRD}$ spectra for $\mathrm{LiNiO}_{2}$ and $\mathrm{LiNi}_{0.75} \mathrm{Mg}_{0.25} \mathrm{O}_{2}$

Figure 3 shows the XRD patterns of $\mathrm{LiNi}_{0.75} \mathrm{Mg}_{0.25} \mathrm{O}_{2}$. It can be seen from the patterns that all diffraction peaks are very strong, which indicate that the samples have good crystal structure. The diffraction peaks are closely matched 
with those of $\mathrm{LiNiO}_{2}$. No impurities were observed in the XRD patterns. This indicates that the element Mg is well substituted for $\mathrm{Ni}$ in $\mathrm{LiNi}_{0.75} \mathrm{Mg}_{0.25} \mathrm{O}_{2}$. Hence, it is thought that the solid state reaction process is quite effective to synthesize multi element-containing oxides and carbonates [9-10].

Table 1:- Lattice constants $(\mathrm{a}, \mathrm{c})$ and c/a ratio for $\mathrm{LiNiO}_{2}$ and $\mathrm{LiNi}_{0.75} \mathrm{Mg}_{0.25} \mathrm{O}_{2}$

\begin{tabular}{|c|c|c|c|c|c|}
\hline Material & $\mathbf{a} \stackrel{\mathbf{A}}{\mathbf{c} \AA}$ & $\mathbf{c} / \mathbf{a}$ & $\begin{array}{c}\text { Crystallite size } \\
(\mathbf{n m})\end{array}$ & Space group \\
\hline $\mathrm{LiNiO}_{2}$ & 2.581 & 14.918 & 5.779 & 42.96 & rhombohedral $(R \overline{3} m)$ \\
\hline $\mathrm{LiNi}_{0.75} \mathrm{Mg}_{0.25} \mathrm{O}_{2}$ & 2.501 & 14.930 & 5.969 & 40.21 & rhombohedral $(R \overline{3} m)$ \\
\hline
\end{tabular}

we calculated the crystallite size at different orientations for these materials from their line width in the XRD pattern by using Debye-Scherrer's formula: $D=0.9 \lambda / \beta \operatorname{Cos} \theta$, where $\lambda$ is the wavelength of the $X$-ray used $(1.54 \AA)$, $\beta$ is the full width half maximum in radians, $\theta$ is Bragg's angle. In short, the crystal structure of the material cannot be changed by Magnesium doping. However, the crystal parameters were influenced. The calculated lattice parameters a, c, c/a and unit-cell volume are summarized in Table 1.

Field Effect Scanning Electron Microscope Observations:-

The field effect scanning electron microscope (FESEM) is used to study the surface morphology of the sample. It is an electron microscope and it takes the images of the surface of the samples by scanning it with a high energy beam of electrons. The FESEM can produce very high-resolution images of the sample surface, revealing details of the order less than $1 \mathrm{~nm}$ in size. This also produce images of high resolution, which means that closely spaced features can be examined at high magnification.

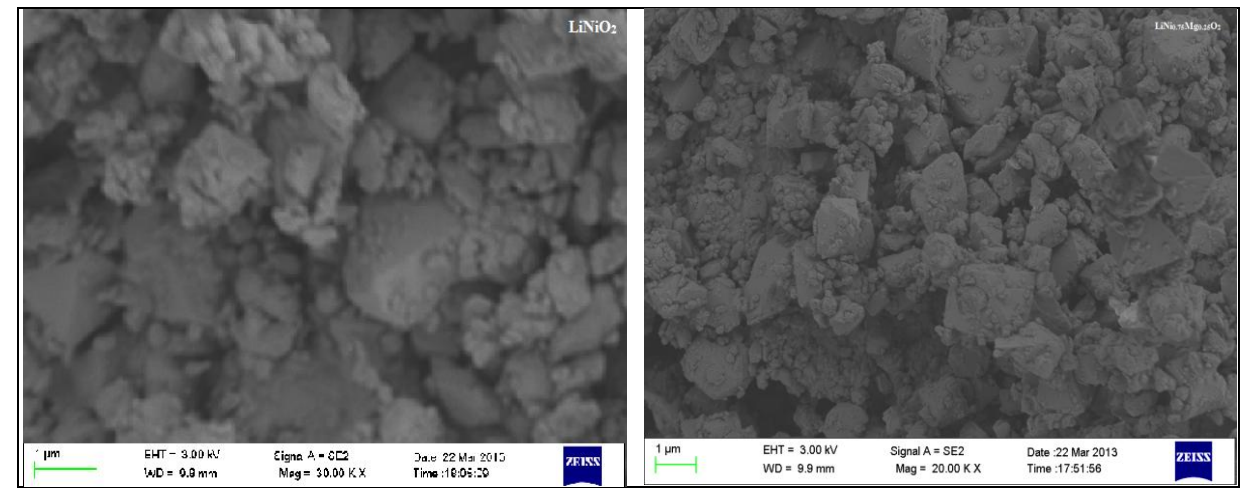

Figure 4:- FESEM images for $\mathrm{LiNiO}_{2}$ and $\mathrm{LiNi}_{0.75} \mathrm{Mg}_{0.25} \mathrm{O}_{2}$

The field effect scanning electron micrographs of $\mathrm{LiNiO}_{2}$ and $\mathrm{LiNi}_{0.75} \mathrm{Mg}_{0.25} \mathrm{O}_{2}$ calcined sample at $800{ }^{0} \mathrm{C}$ for $24 \mathrm{~h}$ in air are presented in Figure 4. The powder of pure $\mathrm{LiNiO}_{2}$ consists of quite small particles of uniform size. The powders calcined for both the compounds comprised of particles of similar shape and size. The particles are generally in the form of smooth-edged polyhedra and their average size is approximately $1.5-2 \mu \mathrm{m}$. This unique morphology is advantageous for electrode materials, because it allows the electrochemical performance to be improved.

\section{Fourier Transform Infrared spectra observations:-}

Typical FT-IR spectra of $\mathrm{LiNiO}_{2}$ and $\mathrm{LiNi}_{0.75} \mathrm{Mg}_{0.25} \mathrm{O}_{2}$ materials synthesized by solid state reaction method are depicted in Figure 5. The FT-IR spectra of the powders displayed the predominance of the stretching modes and the IR resonant frequency of $\mathrm{LiO}_{6}$ octahedra located between 400 and $460 \mathrm{~cm}^{-1}$. There are four infrared active vibrations such as $2 \mathrm{~A}_{2 \mathrm{u}}+2 \mathrm{E}_{\mathrm{u}}$ for the $D_{3 d}^{5}$ group based on group theory analysis [11]. The Wyckoff sites 3(a) and 3(b) consist of transition metal cations (i.e., $\mathrm{Ni}, \mathrm{Mg}$ ) and lithium ions respectively. The $\mathrm{LiNi}_{0.75} \mathrm{Mg}_{0.25} \mathrm{O}_{2}$ materials are separated into $\mathrm{LiO}_{2}$ and $\mathrm{MgO}_{2}$ layers which can be identified in the range of 400-600 $\mathrm{cm}^{-1}$. The band observed around $500 \mathrm{~cm}^{-}$ ${ }^{1}$ may be assigned to the asymmetric stretching modes of $\mathrm{Mg}-\mathrm{O}$ bonds in $\mathrm{MgO}_{6}$ octahedra and the other band around $550 \mathrm{~cm}^{-1}$ may be attributed to the O-Mg-O bending modes [12]. The broadening of FT-IR bands is due to the cation mixing in the crystal layers. When Magnesium substitution increases, the stretching and bending mode frequencies slightly shift to higher wavenumber regions, which may be attributed to a change in $\mathrm{Mg}-\mathrm{O}$ covalency [13]. 


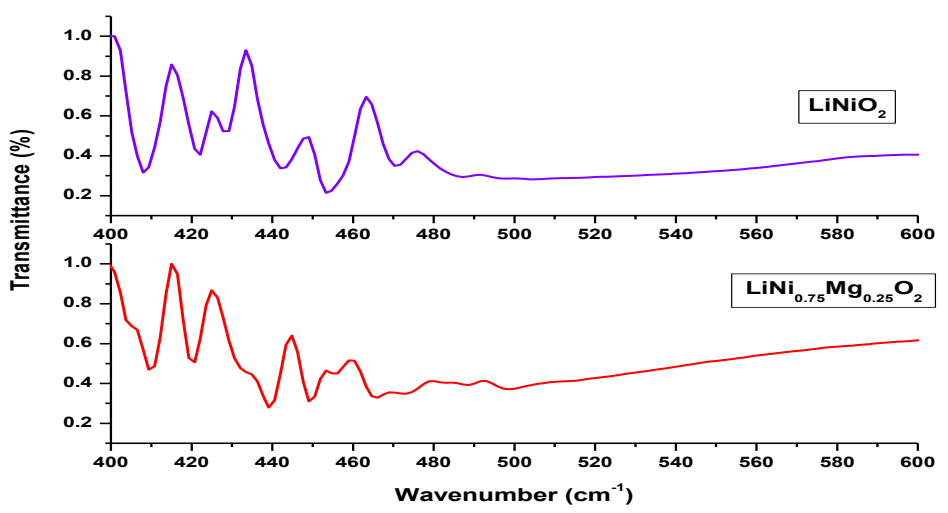

Figure 5:- FTIR spectra for $\mathrm{LiNiO}_{2}$ and $\mathrm{LiNi}_{0.75} \mathrm{Mg}_{0.25} \mathrm{O}_{2}$

The frequency shift of both the stretching and bending modes as a function of the magnesium doping leads to the cationic disorder in the $\left(\mathrm{Ni}_{0.75} \mathrm{Mg}_{0.25}\right) \mathrm{O}_{2}$ slabs. The frequency shift of the $\mathrm{LiO}_{6}$ mode has two origins:

1. The slight expansion of the interslab distance ( $c_{\text {hex }}$ cell parameter) with increasing temperature.

2. The small mixing of $\mathrm{Li}-\mathrm{O}$ stretching and $\mathrm{O}-\mathrm{Ni}-\mathrm{O}$ bending motion present in the low-wavenumber peak.

Figure 5 shows the variation of the frequencies of the high-wavenumber IR-modes with the Co content in $\mathrm{Ni}_{0.75} \mathrm{Mg}_{0.25} \mathrm{O}_{2}$ oxides. [14].

\section{Conclusions:-}

By adopting solid state reaction method, we could successfully synthesize the two compounds $\mathrm{LiNiO}_{2}$ and $\mathrm{LiNi}_{0.75} \mathrm{Mg}_{0.25} \mathrm{O}_{2}$ in the present study. Using this method, the particles were successfully obtained with homogeneous distribution. X-ray diffraction patterns confirmed that the synthesized materials have a well developed layered $\alpha-\mathrm{NaFeO}_{2}$ structure. The material with $\mathrm{Mg}$ stoichiometry had better hexagonal ordering compared to the $\mathrm{LiNiO}_{2}$ and the FT-IR results confirmed the presence of M-O bonds in $\mathrm{MO}_{6}$ octahedra. The FESEM images showed that the agglomerations are of well crystalline submicron particles of size 1.5-2 $\mu \mathrm{m}$. The powders of pure $\mathrm{LiNiO}_{2}$ and $\mathrm{LiNi}_{0.75} \mathrm{Mg}_{0.25} \mathrm{O}_{2}$ consisted of quite small particles of uniform size.

\section{Acknowledgement:-}

The authors (N. Murali and S. J. Margarette) gratefully acknowledge the financial support of University Grants Commission, New Delhi, India through UGC-SAP and MAMS fellowships respectively for this research work.

\section{References:-}

1. Y. Makimura, T. Ohzuku, Journal of Power Sources, 119-121 (2003) 156-160.

2. M. Broussely, F. Perton, P. Biensan, J.M. Bodet, J. Labat, A. Lecerf, C. Delmas, A. Rougier, J.P. Peres, Journal of Power Sources, 54 (1995) 109-114.

3. P. Kalyani, N. Kalaiselvi, N. Muniyandi, J. Power Sources 111 (2002) 232-238.

4. Y. Makimura, T. Ohzuku, Journal of Power Sources, 119-121 (2003) 156-160.

5. M. Broussely, F. Perton, P. Biensan, J.M. Bodet, J. Labat, A. Lecerf, C. Delmas, A. Rougier, J.P. Peres, Journal of Power Sources, 54 (1995) 109-114.

6. P. Periasamy, N. Kalaiselvi, R. Thirunakaran, T. Premkumar, N.G. Renganathan, M. Raghavan, N. Muniyandi, Int. J. Inorg. Mater. 3 (2001) 401-407.

7. J.R. Dahn, V. von Sacken, C.A. Michal, Solid State Ionics 44 (1990) 87.

8. P. Kalyani, N. Kalaiselvi, Science and Technology of Advanced Materials 6 (2005) 689-703

9. H. Tukamoto and A. R. West, J. Electrochem. Soc. 144, 3164 (1997)

10. Y. I. Jang, B. Huang, H. Wang, D. R. Sadoway, G. Ceder, Y. M. Chiang, H. Liu, and H. Tamura, J. Electrochem. Soc. 146, 862 (1999).

11. D. Linden, Handbook of Batteries, Mc Graw Hill Book Co, NY, 1984, p. 2.3.

12. A. Rougier, G. A. Nazri, C. Julien, Ionics 3 (1997) 170.

13. C. Julien, M. Massot, Phys. Chem. Chem. Phys. 4 (2002) 4226.

14. C. Julien, C. Letranchant, S. Rangan, M. Lemal, S. Ziolkiewicz, S. Castro-Garcia, L. El-Farh, M. Benkaddour, Mater. Sci. Eng. B 76 (2000) 145. 